\title{
Upaya Peningkatan Kemampuan Mengenal Huruf dengan Media Kartu Huruf Usia 5-6 Tahun
}

\author{
Paridah $^{\bowtie 1}$, Joni ${ }^{2}$, Dedi Ahmadi ${ }^{3}$ \\ $(1,2)$ Pendidikan Guru Pendidikan Anak Usia Dini, Universitas Pahlawan Tuanku Tambusai
}

$\triangle$ Corresponding author

[paridaaja96@gmail.com]

\begin{abstract}
Abstrak
Penelitian ini bertujuan untuk meningkatkan kemampuan mengenal huruf usia 5-6 tahun. Penelitian ini menggunakan model penelitian 2 siklus. Subjek penelitian yaitu 15 aanak terdiri dari 7 anak laki-laki dan 8 anak perempuan. Hal ini dilatar belakangi oleh rendahnya kemampuan anak dalam mengenal huruf di RA Habiby. Teknik pengumpulan data penelitian yaitu berupa observasi dan dokumentasi. Instrumen penelitian yang digunakan yaitu lembar obsevasi yang berbentuk cheklist. Teknik analisis data dilakukan melalui deskriptif kuantitatif. Hasil penelitian menunjukkan bahwa media kartu huruf dapat meningkatkan kemampuan mengenal huruf pada anak usia 5-6 tahun. Pelaksanaan penerapan media kartu huruf siklus 1 ke siklus 2 sebesar $53 \% \mathrm{MB}$, dan meningkat dari siklus I ke siklus 2 sebesar 33\% MB dan 66,6\% BSH. Langkahlangkah penggunaan media kartu huruf dapat meningkatkan kemempuan mengenal huruf sebagai berikut: 1 , Setiap kelompok memperoleh kartu huruf, 2. Guru memperkenalkan huruf vokal terlebih dahulu, 3, mengenalkan huruf konsonan, 4. Anak dibimbing untuk menyebutkan huruf kemudian disatuakan menjadi kata.
\end{abstract}

Kata Kunci: Kemampuan Mengenal Huruf; Media Kartu Huruf; Kemampuan Mengenal Huruf

\begin{abstract}
This studi aims to improve the ability to recognize letters in children aged 5-6 years, using letter cards in RA Habiby kusau makmur village. This studi used s two cycle research model. The research subjects were 15 children in group B consisting of 7 boys and 8 girls. The data collection techniques of this research areobservation and documentation. The research instrument used is in the form of an observation sheet in the form of a checklist. The indicator studied indicates the symbol of the sound of a letters. The data analysis techniques was carried out through quantitative descriptive. The result dhowed the letter card media could improve the ability to recognize in the preaction stage, the average percentage of achievement for new children was $73 \%$ undeveloped and $26 \%$ Start developing, in the implementation of cycle 1 the percentage achieved was $46 \%$ Start developing, and the increase from cycle 10 the cycle 2 was $33 \%$. The steps for using letters card media can improve the ability to recognize letters as follows: 1) Each group gets letter card, 2) The teacher introduces vowels first, 3) introduces consonant, 4) The children guided to mention the sound of the letters, 5) Children guided to say the letters then put together into word.
\end{abstract}

\section{Keyword: The Ability To Recognize Letters; Letter Card Media; The Ability To Recognize Letters}

\section{PENDAHULUAN}

Pendidikan anak usia dini merupakan kunci pokok pendidikan sealnjutnya, oleh sebab itu telah diatur dalam Undang-undang KEMENDIKBUD no 20 pasal 1 ayat 14 tentang sistem pendidikan nasional dinyatakan bahwa Pendidikan Anak Usia Dini (PAUD) adalah salah satu upaya pembinaan yang dilakukan melalui pemberian rangsangan ditujukan rangsangan pendidikan untuk membantu pertumbuhan dan perkembangan jasmani dn rohani agar anak memiliki kesiapan dalam pendidikan lebih lanjut.

Berdasarkan hasil observasi yang dilaksanakan pada anak usia5-6 tahun di RA Habiby desa Kusau Makmur Kecamatan Tapung hulu dalam kegiatan pembelajaran mengenal huruf masih rendah. Oleh karena itu penulis melakukan penelitian yang berjudul Upaya Meningkatkan Kemampuan Menegenal Huruf Usia 5-6 tahun. melalui perkembangan kemampuan anak dalam mengenal huruf di RA Habiby adalah latar belakang penelitian ini. Sealin itu rendahnya kemampuan anak dalam mengenal huruf dan media pembelajaran yang kurang menarik sehingga perlu ditingkatkan dengan media kartu huruf. Dari fenomena tersebut penulis mengadkan penelitian tentang upaya peningkatan kemampuan bahasa dalam mengenal huruf usia 5-6 tahun di RAHabiby desa Kusau Makmur.

Penggunaan media kartu huruf dan penerapan kartu huruf dengan metode permaianan kartu huruf diharapkan dapat meningkatkan kemampuan bahasa anak dalam mengenal huruf. Penelitian ini bertujuan 
untuk meningkatkan kemampuan anak dlam mengenalhuruf usia 5-6 tahun. Perkembangan bahasa anak usia dini menurut Mulyono (2003) mengatakan bahwa membaca adalah pengenalan simbol-simbol bahasa tulis yang merupakan stimulus membantu proses mengingat tentang apa yang dibaca untuk memberi pengertian melalui pengealaman yang dimiliki.

Upaya peningkatan kemampuan mengenal huruf dengan media kartu huruf diharapkan dapat membentu mempermudah guru-guru PAUD untuk memperkenalkan huruf dengan cara yang lebih menyenangkan dan hasil yang efektif. Untuk itu penelitian tindakan kelas yang menggunakan media kartu huruf sangan relevan untuk digunakan dalam proses pembelajaran di RA Habiby desa Kusau Makmur, Kecamatan Tapung Hulu Kabupaten Kampar tahun ajaran 2020/2021.

Bahasa pada hakikatnya adalah ucapan, pikiranan dan perasaan manusia secara teratur yang mempergunakan bunyi sebagai alatnya (Depdiknas, 2005), Menurut Harun Rasyid dan Suratno (2009) bahasa adalah struktur dn makna dan bebas dari penggunaannya, sebagai tanda yang menyimpulkan suatu tujuaan. Menurut kamus bahasa indonesia (Hasan Alwi, 2002 bahasa berarti sistem lambang bunyi yang digunakan semua orang untuk bekerja sama, berinteraksi, dan mengidntifikasi diri dalam bentuk percakapan yang baik, tingkah laku yang baik dan sopan santun yang baik. Kesimpulan dari pendapat para ahli diatas penulis menyimpulkan bahwa bahasa adalah suatu cara atau alat untuk mendapatkan atau memberikan informasi yang dibutuhkan dalam kehidupan bermasyarakat baik anak kecil maupun orang dewasa.

\section{METODE PENELITIAN}

Penelitian ini menggunakan metode Penelitian Tindakan Kelas (PTK) Penelitian Dilakukan 2 siklus, dalam satu siklus akan dilaksanakan dua kali pertemuan. Subjek penelitian yakni 15 anak terdiri dari 7 anak laki-laki dan 8 anak perempuan siswa RA Habiby usia 5-6 tahun. Teknik pengumpulan data dengan observasi dan dokumentasi, menggunakan lembar observasi berupa checklist, indikator yang diteliti indikator penyebutan lambang bunyi huruf. Teknik analisis melalui deskriptif kuantitatif. Pengambilan data dan pengembangan instrumen menggunakan dokumentasi yaitu kegiatan permainan kartu huruf didokumntasikan baik berupa foto maupun vidio sehingga dapat melihat perkembangan anak persiklus nya dengan baik dan efektif. penelitian dibantu oleh observer yaitu ibu Maznah guru kelas kelompok B, yang memberikan informasi tentang anak- anak yang sedang mengikuti proses pembelajaran. peneliti yang mengamati kegiatan guru / peneliti mengajar dan menilai hasil kerja anak dalam mengenal huruf dengan bermain kartu huruf.

Prosedur penelitian berdasarkan pada bagan alur penelitian Arikunto, yang setiap siklusnya terdapat 4 tahapan yaitu : perencanaan ( Pembuatan rencana kegiatan harian, menyiapkan alat dan bahan, serta lembar observasi), pelaksanaan tindakan (implementasi rencana kegiatan harian) ,observasi (pengamatan) dan refleksi, Penelitian dilakukan di RA Habiby desa Kusau Makmur Kecamtan Tapung Hulu Kabupaten Kampar, penelitian dilakukan dimulai tanggal 20 juli sampai dengan agustus 2020.

\section{HASIL DAN PEMBAHASAN \\ Deskripsi Pra Tindakan}

Sebelum melaksanakan penelitian pada siklus I, terlebih dahulu peneliti mencari data awal nilai kemampuan bahasa dalam mengenal huruf siswa RA Habiby Desa Kusau Makmur, Kecamaatan Tapung Hulu, Kabupaten Kampar. Untuk mengetahui ada tidaknya peningkatan kemampuan bahasa dalam mengenal huruf pada siswa kelompok B. Peneliti terlebih dahulu melakukan tindakan awal, yaitu melakukan observasi kemampuan bahasa dalam mengenal huruf siswa tanpa menerapkan metode permaianan kartu huruf.

\section{Deskripsi Hasil Tindakan Tiap Siklus Siklus I}

Suklus 1 dilaksanakan 2 pertemuan terdiri dari rerencanaan, pelaksanaan, observasi dan refleksi. Hasil observasi aktifitas mengajar guru selama pembelajaran kemampuan bahasa dalam mengenal huruf menggunakan metode permainan kartu huruf disetiap proses pembelajaran menjelang waktu istirahat. Peneliti juga mengamati aktifitas anak selama pembelajaran kemampuan bahasa dalam mengenal huruf menggunakan metode permainan kartu huruf. Kegiatan observasi dilakukan dari awal hingga akhir pembelajaran secara cermat dengan berpedoman pada lembar observasi yang telah disiapkan oleh peneliti dan guru sebagai kolaborator.

Dari data penilaian kemampuan bahasa dalam mengenal huruf sebelum penelitian atau pra tindakan masih rendah dari 15 anak 73,3\% belum berkembang (BB) dan 26,6\% mulai berkembang (MB). Setelah siklus 1 sebesar 46,6\% mulai berkembang (MB). Lihat tabel 1.

\section{Tabel 1. Nilai Aktifitas Belajar Anak Siklus I Pertemuan 1}




\begin{tabular}{|c|c|c|c|c|c|}
\hline \multirow[t]{2}{*}{ NO } & \multirow{2}{*}{ Nama } & \multicolumn{4}{|c|}{ PENILAIAN } \\
\hline & & BB & MB & BSH & BSH \\
\hline 1 & $\mathrm{Al}$ & $\sqrt{ }$ & & & \\
\hline 2 & $\mathrm{Ai}$ & $\sqrt{ }$ & & & \\
\hline 3 & $\mathrm{Aq}$ & & $\sqrt{ }$ & & \\
\hline 4 & $\mathrm{Di}$ & & $\sqrt{ }$ & & \\
\hline 5 & $\mathrm{Br}$ & & $\sqrt{ }$ & & \\
\hline 6 & $\mathrm{Fi}$ & $\sqrt{ }$ & & & \\
\hline 7 & Id & & $\sqrt{ }$ & & \\
\hline 8 & Ma & $\sqrt{ }$ & & & \\
\hline 9 & $\mathrm{Na}$ & & $\sqrt{ }$ & & \\
\hline 10 & $\mathrm{Na}$ & & $\sqrt{ }$ & & \\
\hline 11 & $\mathrm{Ra}$ & $\sqrt{ }$ & & & \\
\hline 12 & Ro & & $\sqrt{ }$ & & \\
\hline 13 & $\mathrm{Ra}$ & $\sqrt{ }$ & & & \\
\hline 14 & $\mathrm{Ta}$ & $\sqrt{ }$ & & & \\
\hline \multirow[t]{3}{*}{15} & $\mathrm{Ti}$ & $\sqrt{ }$ & & & \\
\hline & Jumlah & 8 & 7 & & \\
\hline & Persentase & $53,3 \%$ & $46,6 \%$ & & \\
\hline
\end{tabular}

Tabel 2. Hasil Deskriptif Nilai Evluasi Siklus I

\begin{tabular}{cll}
\hline NO & \multicolumn{1}{c}{ Aspek yang diamati } & Hasil evaluasi \\
\hline $\mathbf{1}$ & Nilai tertinggi & MB \\
\hline $\mathbf{2}$ & Nilai terendah & BB \\
\hline 3 & Jumlah diswa yang mencapai standar pencapaian & 4 orang \\
\hline 4 & Jumlah diswa yang tidak mencapai standar pencapaian & 11 orang \\
\hline
\end{tabular}

Dari tabel 2 Deskripsi nilai evaluasi siklus 1, anak sudah mencapai perkmbangan dalam mengenal huruf 4 anak mulai berkembang (MB) dan 11 anak belum berkembang (BB).

\section{Siklus 2}

Guru merencanakan pembelajaran dengan mengacu pada RPPM dan RPPH yang sudah dirumuskan, setiap harinya guru menerapkan apa yang sudah direncanakan dengan melihat situasi dan kondisi dilapangan. Siklus 1 direncanakan 2 kali pertemuan setiap pertemuan dengan alokasi waktu $3 \times 35$ menit ( 3 jam pelajaran) berikut perencanaan yang dilakukan guru: a) membuat rencana pelaksanaan pembelajaran kemampuan bahasa dalam mengenal huruf, b) menyiapkan media pembelajaran, c) menyiapkan lembar observasi. Pada pelaksanaan diawali dengan kegiatan pendahuluan dilakukan kurang lebih 5 menit, guru mengawali pembelajaran dengan mengucapkan salam, bertanya kabar kemuadian menyiapkan siswa secara fisik maupun psikis untuk mengikuti proses pembelajaran. Guru melakukan apersepsi dengan menunjukan alat peraga yaitu kartu huruf dan pembelajaran dan memimpin doa sebelum belajar serta doa harian lainnya. Kegiatan inti guru mengajak siswa untuk memperhatikan kartu huruf yang sudah disediakan kemudian guru membimbing anak untuk menyebutkan bunyi huruf sesuai dengan bentuknya. Kemudian mencari kartu huruf yang disebutkan bunyi nya secara kelompok. Setelah semua kelompok menyelesaikan permaianan kartu huruf guru membagikan lembar kerja siswa. dan anak menyelesaikan tugasnya masing-masing. Kegiatan penutup, kegiatan penutup dilakukan sekitar 10 menit, pada kegiatan penutup anak diminta untuk mengingat kembali bentuk dan bunyi huruf yang telah dilaksanakan pada kegiatan inti untuk dievaluasi dipertemuan akan datang, selanjutnya anak diberi kesempatan untuk menyampaikan kesulitan yang ditemui disaat pembelajaran.

Tabel 3. Hasil belajar anak pada siklus 2

\begin{tabular}{lll}
\hline No & Aspek yang diamati & Hasil evaluasi \\
\hline $\mathbf{1}$ & Nilai tertinggi & $\mathrm{BSH}$ \\
\hline $\mathbf{2}$ & Nilai terendah & $\mathrm{BB}$ \\
\hline $\mathbf{3}$ & Jumlah siswa yang mencapai standar pencapaian & 4 orang \\
\hline $\mathbf{4}$ & Jumlah siswa yang mencapai standar pencapaian & 11 orang \\
\hline
\end{tabular}

Hasil observasi aktifitas mengajar guru. Kegiatan observasi dilakukan dari awal hingga akhir pembelajaran secara cermat dengan berpedoman pada lembar observasi yang telah disiapkan oleh peneliti dan guru sebagai kolaborator. Sedangkan aktifitas belajar anak yang diamati selama pembelajaran kemampuan bahasa anak dalam mengenal huruf sesuai lembar observasi yang telah disediakan oleh peneliti dan guru. Hasil belajar anak dapat dilihat dari tabel 3. 


\section{Perbandingan Hasil Tindakan Antar Siklus}

Hasil yang diperoleh pada pra observasi dan pelaksanaan siklus I apabila dibandingkan terlihat sudah ada peningkatan, namun belum mencapai indikator keberhasilan yang diharapkan peneliti, sehingga perlu diadakan siklus 2. Hal ini disebabkan pada pelaksanaan siklus 1 terdapat beberapa kendala yang dihadapi pada saat pelaksanaan siklus 1, sehingga perlu diadakan suatu perbaikan dalam siklus 2 agar indikator keberhasilan yang diharapkan dapat tercapai. Kendala yang dihadapi pada pelaksanaan siklus 1 yaitu; pembelajan klasikal kurang efektif karen aanak hanya ikut-ikutan saja, membuat keaktifan anak kurang terlihat. Media pembelajaran kurang memadai sehingga anak bosan dengan pembelajaran yang monoton.

Pada siklus 2 pertemuan 2 guru merencanakan pembelajaran dengan mengacu pada RPPM dan RPPH yang sudah dirumuskan, setiap harinya guru menerapkan apa yang sudah direncanakan dengan melihat situasi dan kondisi dilapangan. Siklus 1 direncanakan 2 kali pertemuan setiap pertemuan dengan alokasi waktu 3x35 menit ( 3 jam pelajaran). Perencanaan yang dilakukan guru yaitu membuat rencana pelaksanaan pembelajaran kemampuan bahasa dalam mengenal huruf, menyiapkan media pembelajaran, dan menyiapkan lembar observasi.

Pada kegiatan pelaksanaan diawali dengan kegiatan pendahuluan yaitu; dilakukan kurang lebih 5 menit, guru mengawali pembelajaran dengan mengucapkan salam, bertanya kabar kemuadian menyiapkan siswa secara fisik maupun psikis untuk mengikuti proses pembelajaran. Guru megajukan pertanyaan "Anakanak apa kalian ketahui tentang anggota tubuh dan fungsi anggota tubuh? Kemudian buguru menyusun kartu huru dengan kata: $M$ a t a, dan meminta anak menyebutkan huruf nya satu-persatu

Selanjutnya pada kegiatan Inti guru mengajak siswa untuk memperhatikan kartu huruf yang sudah disediakan kemudian guru membimbing anak untuk menyebutkan bunyi huruf sesuai dengan bentuknya. Kemudian mencari kartu huruf yang disebutkan bunyi nya secara kelompok. Setelah semua kelompok menyelesaikan permaianan kartu huruf guru membagikan lembar kerja siswa. dan anak menyelesaikan tugasnya masing-masing.

Kegiatan penutup dilakukan sekitar 10 menit, pada kegiatan penutup anak diminta untuk mengingat kembali bentuk dan bunyi huruf yang telah dilaksanakan pada kegiatan inti untuk dievaluasi dipertemuan akan datang, selanjutnya anak diberi kesempatan untuk menyampaikan kesulitan yang ditemui disaat pembelajaran.

Hasil Observasi aktifitas mengajar guru dilakukan dari awal hingga akhir pembelajaran secara cermat dengan berpedoman pada lembar observasi yang telah disiapkan oleh peneliti dan guru sebagai kolaborator. Sedangkan aktifitas belajar anak yang diamati selama pembelajaran kemampuan bahasa anak dalam mengenal huruf sesuai lembar observasi yang telah disediakan oleh peneliti dan guru. Hasil belajar anak hasil belajar anak dapat dilihat dari tabel 3 nilai belajar anak siklus 2 pertemuan 2

\section{Pembahasan}

Hasil yang diperoleh pada pra observasi dan pelaksanaan siklus I anak sama sekali belum mengenal huruf karena masih awal tahun ajaran baru. Penerapan media kartu huruf dilaksanakan setiap alam proses kegiatan berlangsung dengan diiringi pembelajaran lainnya. Pada siklus 1 pertemuan pertama proses pengenalan bunyi huruf vokal, anak diminta menirukan bunyi huruf dimbing bu guru, kemudian secara bergantian memeganga ditangan masing-masing. Pada pertemuan kedua anak sudah mulai huruf a,i,u,e,o walau terkadang ada salah satu anak yang salh dalam menyebutkan huruif, pertemuan pertama disiklus ke 2 anak sudah mengenal bentujk dari huruf vokal dan mampu menebalkan dan menulis huru vokal secara keseluruhan. Dengan media kartu huruf dan menyebutkan bunyi huruf sesuai yang ada Penelitian ini telah membuktikan bahwa melalui media huruf dapat meningkatkan kemampuan bahasa anak dalam mengenal huruf di RA Habiby Kusau Makmur, Tapunhg Hulu. tahun ajaran 2020/2021.

Temuan yang dijumpai saat penelitian pada aktifitas mengajar guru, pada saat pembelajaran, setiap anak sudah mulai meningkat secara bertahap dari pra siklus kesiklus 1, kemudian dari siklus 1 ke siklus 2 dari menyebutkan huruf dengan media kartu hurufdan mencocokan kartu huruf dengan gambar yang di sediakan, kemudain guru memberikan penjelasan didepan kelas tentang huruf yang akan disebutkan dan di cocokan sesuai gambar. Pada aktifitas belajar anak ditemukan anak yang berinisial Ai penilaian di siklus 1 masih Belum Berkembang Karena anak cenderung tidak fokus dalam kegiatan, selalu berjalan mengelilingi teman nya setelah ditegur dan diminta untuk kembali duduk huruf dan konteksnya. Anak mulai mengenal tanda-tanda yang ada pada benda-benda disekitar dan lingkunganya. Kegiatan pembelajaran membaca dapat dilakukan dengan media kartu huruf, gambar-gambar yang digunakan sebagai media tersebut bisa dari gambar yang ada disekitar lingkungan anak agar anak lebih mudah untuk mengenalinya. Hal ini sesuai dengan pendapat Tadkirotum Musfiroh (2009) yang mengungkapkan bahwa anak TK baru berada pada tahap membaca gambar anak memperhatikan tanda-tanda visual seperti gambar tetapi belum menguasai simbol, dengan melihat gambar, membaca label dengan memperhatikan barang dan gambarnya. Anak menjabarkan gambar/informasi visual lain dalam bentuk satu kalimat. 


\section{SIMPULAN}

Peningkatan kemampuan anak dalam mengenal huruf dapat dildihat dri persentase dari pra siklus 73\% BB dan disiklus ke 2 tidak ada lagi nilai BB. pencapaian anak meningkat menjadi BSH (Berkembang Sesuai Harapan). Media pembelajaran yang menarikakan berpengaruh pada tingkat pencapaian anak dalam belajar.

\section{UCAPAN TERIMA KASIH}

Terimakasih kepada suami, orang tua, dosen pembimbing yang selalu memberikan bimbingan selama penulisan skripsi, dosen penguji yang telah memberikan kritikan dan saran dalam kesempurnaan skripsi ini, kepala sekolah RA Habiby yang memberikan izin untuk mengadakan penelitian, guru RA Habiby sebagai teman sejawat yang membentu melakukan observasi.

\section{DAFTAR PUSTAKA}

Abdurrahaman, Mulyono (2003:83) Pendidikan belajar bagi ank berkesulitan belajar, Jakarta: Rineka Cipta

Arikunto, s. (2009) Prosedur penelitian. Jakarta, Rineka Cipta.

Dafa. (2010) Langkah -Langkah mengenal huruf. Jakarta: Grafindo

Depdiknas, (2004) kurikulum berbasis TK dan RA, Jakarta: Depdiknas.

Dykstra (1992) Studying of biological education. pp165-169

Ebrahim GJ (1982) Child health in Achanging Environmen. London. Macmillan press.LTD keluarga

Guma dan lincoln dalam Hamdani dan hermala (2008: 70) Bab II kajian pustaka, Teori Pendidikan Anak Usia Dini

Gunarti, winda dkk (2011) Metode pengembangan prilaku dan kemampuan dasar Anak Usia Dini, Jakarta Universitas Terbuka. Hartati

Hasan Alwi (2020) : 88 Kamus Bahasa Indonesia.

Madyawati (2016) Strategi Pengembangan Bahasa Pada Anak. Jakarta: Prenda grup.

Mashitoh, dkk. 2004, Strategi pembelajaran TK Jakarta: Penerbit Universitas Terbuka.

Musfiroh (2008:7) Bermain sambil belajar, Direktori file Perkembangan bahsa Anak Usia Dini

Rusniah (2017) Meningkatkan perkembangan bahasa Indonesia anak usia dini, Jakarta: Gramedia pustaka utama

Arikunto. (2007) Penelitian Tindakan Kelas, Penerbit Bumiaksara, Jakarta.

Susanto. A (2010) Perkembangan Anak Usia Dini, Jakarta: Kencana Prenada Group.

Suhartono (2005) Penegembangan Keterampilan Berbicara Anak Usia Dini Jakarta: Dirjen Dikti Depdikbud.

Seefeldt Etianingsih (2015:165) ejournal.unsri.ac.id, belajar huruf adalah kurikulum taman kanak -kanak yang berulang dan bermakna. Metode Penegembnagan Perilaku dan Kemampuan Dasar Anak Usia Dini. Jakarta. Penerbit Universitas Terbuka. 